\title{
A new year brings renewed hope
}

SADJ February 2021, Vol. 76 No. 1 p2

NH Wood

Managing Editor of the SADJ



We have seen a decline over the past year in the provision of oral healthcare services to our patients and to our communities. The efforts to curb the spread of the SARS-CoV-2 virus inadvertently left a void in what would have been the normal standard of care. However, we know by now that pre-Covid normality has been relegated to the history books.

The roll-over effect of the lack of oral health care provision cannot yet be determined, but I fear that there may be dire consequences for some of our vulnerable patients, more so in our vulnerable communities.

Access to oral healthcare for many communities was already a challenge already pre-Covid, often necessitating travel to clinics or hospitals far from their homes. Given the restrictions during the various lockdown stages, fear of contracting the virus and other contributing factors, we have seen a further decline in the overall attendance numbers of patients seeking urgent or emergency care.

The fact that many patients could not attend to regular check-up visits, to receive minor procedures or preventive interventions, or to maintenance programs, raises the serious concern that we may see a peak in emergency procedures over the next few months. A detailed study of our own populations is needed to quantify the sequalae of the lockdown, and to assist in designing strategies to provide routine care and prevention, even to the most isolated patients in our society.

However, many of the changes we now see in our own practices and clinics have impacted the profession favorably, most notably within infection control, communication and personal interaction, and also on the teaching and training of various oral healthcare personnel. If we

Neil H Wood: Managing editor. Email: neil.wood@smu.ac.za embrace change and sustain the positive aspects thereof, it will have a meaningful impact on the further growth and development of oral healthcare in South Africa.

It is up to us to take this opportunity to evolve our approaches to oral healthcare, and to develop our preventioncentric stance even further. Irrespective of the setting that we practice in, there are moments when we have the ability to take positive action and contribute to the greater good within the context of oral health care. We all hold a social responsibility towards society.

Our cover page theme for this year relates to masks, thought to be befitting of the pandemic the world is currently struggling with. We will feature a diverse array of masks, all of which serve their own purpose and worn with different intentions. We also welcome submissions from our readers of masks that have significant meanings/symbolism attached.
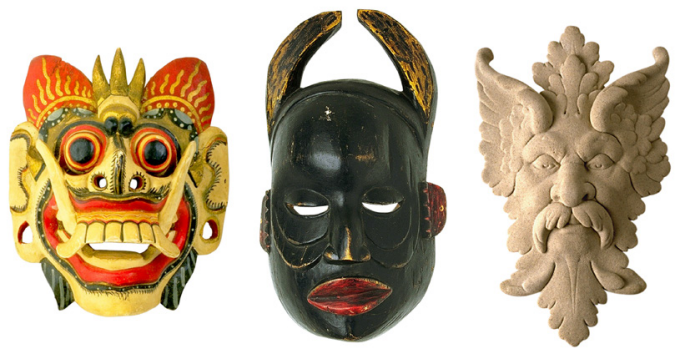

Although we are still facing serious challenges, I wish you well for this year, and may 2021 be prosperous to all. Please enjoy the February 2021 issue of the SADJ filled with interesting content, with thanks also to our regular contributors.

\section{Footnote}

Please be reminded to register on our online platform at https://journals.assaf.org.za/index.php/sadj/index 